\title{
Mediando a alimentação de escolares por meio de uma sequência didática
}

Amanda Magnago Menon*, Marinez Meneghello Passos ${ }^{\star \star}$, Marlize Spagolla Bernardelli**

\section{Resumo}

Este artigo apresenta a estruturação de uma Sequência Didática (SD) com atividades interdisciplinares em torno da temática Nutrição, que visa contribuir para a efetivação de escolhas alimentares saudáveis pelos alunos. A SD foi estruturada por três etapas orientadas pela teoria da Aprendizagem Significativa (AS), nas quais foram propostas sete atividades, ao todo, levando-se em consideração a realidade escolar, e que considera, também, o contexto em que a escola estava inserida. Além disso, assumiu-se a nutrição humana como um tema integrador das disciplinas escolares e conteúdos dos livros didáticos do quinto ano do Ensino Fundamental. Tal elaboração voltou-se para uma turma de escola pública do norte do Paraná, composta por 22 alunos com idade entre nove e onze anos de ambos os sexos. Os dados coletados com a aplicação da Sequência Didática foram categorizados e analisados à luz dos pressupostos teóricos da Análise Textual Discursiva. Este movimento analítico proporcionou concluir que houve uma ampliação da compreensão de conceitos de nutrição por parte dos alunos na perspectiva da Aprendizagem Significativa, fato que os levou a um envolvimento com a temática, motivando-os a buscar uma alimentação adequada e saudável. Além disso, este processo permitiu-nos inferir que com pequenas adaptações esta proposta pode ser utilizada para abordar um tema mais amplo que é a Educação Alimentar e Nutricional.

Palavras-chave: Aprendizagem significativa. Educação alimentar e nutricional. Interdisciplinaridade. Sequência didática.

\footnotetext{
* Mestra em Ensino pela Universidade Estadual do Norte do Paraná - UENP, campus de Cornélio Procópio, Brasil. E-mail: amanda_menon@hotmail.com

* Professora Colaboradora Sênior do Programa de Mestrado Profissional em Ensino - PPGEN. Universidade Estadual do Norte do Paraná - UENP, campus de Cornélio Procópio - e professora Sênior da Universidade Estadual de Londrina - UEL, Brasil. Com o apoio do CNPq. E-mail: marinez@uenp.edu.br

*** Professora aposentada voluntária do Programa de Mestrado Profissional em Ensino - PPGEN. Universidade Estadual do Norte do Paraná - UENP, campus de Cornélio Procópio, Brasil. E-mail: marlizespagolla@uenp.edu.br
} 


\section{Introdução}

O acesso à alimentação adequada é uma das necessidades básicas de todo ser humano, particularmente na fase inicial de sua vida. Uma pessoa começa a desenvolver seus hábitos alimentares desde a primeira infância e recebe influências de fatores fisiológicos, psicológicos, socioculturais e econômicos (SILVEIRA, 2015).

Nesse sentido, considerou-se que a abordagem acerca da nutrição dos estudantes seja relevante na promoção de uma vida promissora. A utilização dessa temática na escola, por meio de ações de Educação Alimentar e Nutricional (EAN), permite que estes conhecimentos estejam presentes durante toda a vida e que se inicie já na infância. No entanto, os conteúdos biológicos da alimentação não são o único segmento a serem considerados para a abordagem da EAN, pois o retrato cultural e a vivência dos indivíduos possuem forte contribuição para o cenário alimentar de uma sociedade.

Em um levantamento realizado no portal de periódicos e no banco de teses e dissertações da Coordenação de Aperfeiçoamento Pessoal de Nível Superior CAPES $^{1}$, a partir da busca com as palavras-chave "alimentação AND nutrição" (MENON; COELHO NETO; BERNARDELLI, 2018), identificou-se que o desenvolvimento de atividades relacionadas à alimentação e nutrição na disciplina de Ciências é frequentemente realizado. No entanto, por ser um objeto presente nos Parâmetros Curriculares Nacionais (PCN) como tema transversal - Saúde (BRASIL, 1997) - entende-se que o assunto é aplicável a todas as disciplinas. Dos 3.845 trabalhos encontrados, apenas nove apresentavam a articulação da temática com outras disciplinas ou de forma interdisciplinar ${ }^{2}$. Neste contexto, a pesquisa teve $o$ intuito de evidenciar que a EAN é um tema abrangente e habitual, passível de ser abordado de forma interdisciplinar com as demais disciplinas do currículo escolar.

Além disso, a EAN encontra-se como um dos temas integradores da Base Nacional Comum Curricular (BNCC), em vigor a partir de 2018. No documento, temas contemporâneos como esse são destacados como influenciadores da vida humana e são contemplados nas habilidades de todos os componentes curriculares. A recomendação é que os sistemas de ensino e as escolas devem incorporá-los aos currículos e às propostas pedagógicas de modo contextualizado e transversal (BRASIL, 2018).

Mediante o exposto, insere-se a problemática da pesquisa: de que forma a EAN pode ser trabalhada no âmbito interdisciplinar com alunos do Ensino Fundamental, a fim de promover uma Aprendizagem Significativa (AS)? 
Para atender à indagação em questão, foi proposta uma SD com abordagem interdisciplinar em torno da importância da nutrição, visando contribuir para escolhas alimentares saudáveis dos alunos, conforme a realidade da escola e o contexto em que viviam.

A seguir, serão apresentados os referenciais teóricos que nortearam a elaboração da SD, o encaminhamento metodológico, a estrutura do produto educacional e, por fim, algumas considerações e possíveis desdobramentos acerca da SD desenvolvida.

\section{A elaboração da Sequência Didática: alguns destaques}

Ao nascer, todo indivíduo possui o direito à alimentação adequada, o qual é previsto em vários documentos nacionais e internacionais, como na Declaração Universal dos Direitos Humanos (ONU, 1948). No Brasil, a realização desse direito resulta no estabelecimento do conceito de Segurança Alimentar e Nutricional (SAN) ${ }^{3}$.

A abordagem da alimentação como um procedimento alternativo em sala de aula pode colaborar para que os alunos adquiram conhecimentos mais significativos. Conforme evidenciado por Bernardelli (2004, p. 2):

A verdadeira aprendizagem para o aluno está na forma de planejarmos nossa ação didática na proposição dos conteúdos de determinados conhecimentos relacionados, integrando-os e sistematizando-os a partir das experiências vivenciadas pelos alunos. Com isso, estamos desenvolvendo as habilidades necessárias para que possamos resolver determinados problemas com a disciplina. $\mathrm{O}$ procedimento alternativo procura colocar o aluno em posição de pensar por si mesmo, colher dados, discutir ideias, emitir e testar hipóteses, sempre motivado pela identificação do problema, levando-os à aprendizagem alicerçada ao 'encantamento' e pela curiosidade.

Logo, a escola é um ambiente favorável às ações de EAN, pois está envolvida diretamente com todos os campos do aprendizado. Segundo Gallina et al. (2013), o professor é a figura mais apropriada para aplicá-las, pois passa a maior parte do tempo com os alunos, conhece seus interesses e possui um forte laço de confiança, o que o torna capaz de proporcionar uma aprendizagem voltada a fatores que contribuam com os comportamentos alimentares saudáveis a partir da integração de conceitos com as experiências vivenciadas.

Desse modo, acredita-se que cada docente pode ir além de sua própria área de atuação disciplinar, que é possível acontecer na escola um processo de ensino abrangente e com mais sentido para os alunos e para o professor, e que ao perceber quão 
valiosa é a troca de saberes, leva-os a um conhecimento ainda maior de si próprio e de sua posição diante do mundo (ALMEIDA, 2013).

As Diretrizes Curriculares Nacionais (DCN) da Educação Básica retratam a interdisciplinaridade como uma das formas de organização curricular, a qual presume a transferência de métodos de uma disciplina para outra. Em complemento, os PCN descrevem a interdisciplinaridade como uma "[...] complexidade do real e a necessidade de se considerar a teia de relações entre os seus diferentes e contraditórios aspectos" (BRASIL, 2013, p. 30).

Fazenda (1991) indica a interdisciplinaridade como uma problemática vista segundo uma atitude de troca, de diálogo, de buscar diferentes alternativas para maior e melhor compreensão dos estudos do meio, dentre tantas outras atitudes possíveis do professor na procura constante do conhecimento. Desse modo, um trabalho em parceria torna a aprendizagem mútua, manifestada no compartilhamento de falas, espaços, presenças e ausências, na realização em ver a teoria na prática e a prática na teoria.

A EAN pode ser trabalhada em diversas disciplinas do currículo básico (RETONDARIO; NADAL, 2015), entre elas destacam-se: na elaboração de textos na disciplina de Língua Portuguesa, em cálculos de ingestão calórica na disciplina de Matemática e na análise dos processos biológicos em Ciências. Assim, observa-se que o tema não é de responsabilidade e competência de um único professor. Por ser um assunto cotidiano, cabe sua contextualização em todas as disciplinas do currículo escolar.

Diante dessas exposições, evidencia-se a necessidade de uma sistematização da SD, segundo uma teoria de aprendizagem que contribua com a organização das atividades e que favoreça a compreensão dos conteúdos propostos por parte dos alunos participantes. Por isso a sugestão de integração a este movimento de alguns conceitos da Aprendizagem Significativa (AS).

Segundo Ausubel, Novak e Hanesian (1980, p. 34),

A aprendizagem significativa envolve a aquisição de novos significados e os novos significados, por sua vez, são produtos da aprendizagem significativa. Ou seja, a emergência de novos significados no aluno reflete o complemento de um processo de aprendizagem significativa.

Moreira (1999) relata que a AS fornece subsídios para uma estratégia de ensino que busca o desenvolvimento de várias capacidades do aluno, pois além de ser uma 
teoria de aprendizagem oferece diretriz e princípios passíveis de serem colocados em prática. Encontra-se na literatura outras pesquisas que igualmente valorizam a abordagem da AS no Ensino Fundamental, entre elas destaca-se Almeida, Scheunemann e Lopes (2019), que se interessaram em verificar as percepções de professores em formação continuada quanto às contribuições dessa teoria.

Sabe-se que a AS ocorre quando uma nova informação passa a ter significado para o aluno mediante conhecimentos prévios que funcionam como ideias âncoras, chamadas de subsunçores. Segundo Moreira (2011), quando o aluno não possui subsunçores a respeito de um assunto, os organizadores prévios podem servir como ponte e serem utilizados para corroborar a relação entre as novas concepções e os conhecimentos já existentes, transformando o que sabia em função das novas informações.

Dessa forma, o subsunçor fica mais estável, diferenciado e rico em significados, o que facilita a assimilação das novas aprendizagens. Nesse sentido, quando aprende, o aluno torna-se capaz de diferenciar progressivamente e reconciliar integrativamente os novos conhecimentos adquiridos (MOREIRA, 2011). Esses dois processos ocorrem simultaneamente na estrutura cognitiva.

Ausubel (2003, p. 166) descreve o princípio da diferenciação progressiva como uma hierarquização dos conceitos, desde os mais gerais até a relação com os mais específicos, afirmando que "[...] a maioria da aprendizagem e toda a retenção e a organização das matérias é hierárquica por natureza, procedendo de cima para baixo em termos de abstração, generalidade e inclusão”.

O conceito de reconciliação integrativa é designado como "[...] a capacidade de discriminação das diferenças entre os novos materiais de aprendizagem e ideias aparentemente análogas, mas frequentemente conflituosas, na estrutura cognitiva do aprendiz", em um movimento "de baixo para cima” das novas informações incorporadas com as ideias anteriormente apreendidas (AUSUBEL, 2003, p. 170).

Nessa perspectiva, aprender exige intencionalidade, reciprocidade, transposição e mediação de significados. Ao professor, cabe buscar materiais e procedimentos que promovam ações de interesse frente às perspectivas apresentadas pelas ciências, por exemplo: a elaboração de uma SD.

Segundo Zabala (2010, p. 18), uma SD pode ser definida como “[...] um conjunto de atividades ordenadas, estruturadas e articuladas para a realização de certos objetivos educacionais, que tem um princípio e um fim conhecidos tanto pelos professores 
como pelos alunos”, mantendo o caráter unitário e reunindo toda a complexidade da prática, concomitantemente permitindo incluir as três fases de toda intervenção reflexiva: planejamento, aplicação e avaliação.

Destarte, a utilização da SD pode ser um complemento ao uso do livro didático, pois esse tipo de material possibilita a ressignificação de conteúdos por meio de um conjunto de atividades contextualizadas e planejadas para trabalhar um determinado conteúdo, etapa por etapa. Em uma SD, a relação entre professor, alunos e os conteúdos de aprendizagem ocorrem de forma interativa, havendo a possibilidade de repensar e adaptar as atividades em seu percurso.

Essa SD é uma adaptação a partir da Unidade 04 de Zabala (2010), a qual considera os conteúdos conceituais, procedimentais e atitudinais para o desenvolvimento das atividades que, por sua vez, foram desenvolvidas mediante a necessidade e a realidade da comunidade do município no qual a escola estava inserida. Cabe esclarecer que o presente instrumento passou previamente por validação. As atividades foram analisadas, corrigidas e receberam colaborações por parte dos pares e professores em grupos de estudos da Universidade em que esta proposta foi desenvolvida.

\section{Encaminhamento metodológico}

A pesquisa desenvolvida insere-se no âmbito da investigação qualitativa, amplamente utilizada na área de Educação e de Ensino, que fornece estratégias que permitem o estudo de temáticas não estritamente quantificáveis, como os processos de ensino e de aprendizagem de conteúdos científicos (BOGDAN; BIKLEN, 1994).

Os participantes da pesquisa foram 22 alunos de uma turma de quinto ano do Ensino Fundamental de uma escola municipal do norte do Paraná, com idades entre nove e onze anos e de ambos os sexos. As atividades elaboradas tiveram o intuito de apresentar aos alunos conteúdos de EAN, em que as novas informações pudessem ser pensadas juntamente com a realidade da escola e da sociedade em questão.

Após a aceitação da escola para a aplicação da pesquisa e antes de iniciar os encontros, os pais e/ou responsáveis dos menores foram comunicados por meio de um termo de consentimento, solicitando a autorização para a participação do aluno e respeitando todos os aspectos éticos previstos para uma pesquisa com crianças (KRAMER, 2002). A proposta da SD foi igualmente apresentada aos alunos em 
conjunto com a professora regente, de modo que a classe pudesse ter conhecimento prévio a respeito das atividades que seriam desenvolvidas.

Quanto aos instrumentos para a coleta de dados, foi desenvolvido um diário de bordo e realizados registros fotográficos, gravações em vídeo e transcrição dos áudios em atividades pontuais da SD, os quais foram utilizados para posterior análise ${ }^{4}$. A SD foi aplicada em sete encontros, visto que cada atividade precisou de um encontro para o respectivo desenvolvimento.

\section{A Sequência Didática como produto educacional}

Segundo as regulamentações legais da CAPES, os programas de mestrado profissional na Área de Ensino necessitam gerar produtos educacionais que sirvam como materiais educativos para uso em escolas públicas do País, além das dissertações exigidas ao final do curso. Tais produtos são aplicados em condições reais de sala de aula, sendo obrigatória sua validação e registro com livre acesso em sistemas de Educação (BRASIL, 2016). Nesse sentido, a SD é um dos exemplos encontrados no documento como produtos educacionais aceitos pela CAPES.

Assim, para estruturar a SD com atividades que pudessem atingir diferentes objetivos, considerou-se relevante conhecer a natureza das tipologias dos conteúdos a serem abordados, conforme Zabala (2010):

1. Conteúdos conceituais: referem-se "[...] ao conjunto de fatos, objetos ou símbolos que têm características comuns" (ZABALA, 2010, p. 42), relacionados aos conceitos e princípios. Estes conteúdos objetivam a identificação do objeto de estudo de acordo com suas definições e estão voltados para o "saber" do aluno.

2. Conteúdos procedimentais: são "[...] um conjunto de ações ordenadas com um fim, ou seja, dirigidas para a realização de um objetivo" (ZABALA, 2010, p. 44), relacionados aos modos de construção do conhecimento, por exemplo, ler, desenhar, calcular, observar, classificar, recortar, saltar, inferir, espetar etc. Eles estão relacionados com o "saber fazer" dos alunos.

3. Conteúdos atitudinais: são as "[...] atitudes que o aluno toma frente a uma situação-problema" (ZABALA, 2010, p. 46), como os valores (princípios ou ideias que permitem uma pessoa emitir suas concepções a respeito de suas condutas e sentidos, entre eles a tolerância ao próximo); atitudes (a forma 
que cada indivíduo reage de acordo com seus juízos de valor, entre elas a participação das atividades propostas na escola); normas (regras de comportamento a serem seguidas em determinadas situações, como ter consciência do que pode ou não ser feito no ambiente escolar), referentes à construção dos conhecimentos. Estes conteúdos relacionam-se com o "saber ser" dos alunos.

Logo, reconhecer os conteúdos de aprendizagem de acordo com sua natureza é um instrumento apropriado para compreender o que está acontecendo em sala de aula (COOL et al., 1998), fato que permite a observação do trabalho desenvolvido pelo professor, suas respectivas finalidades educativas, se os alunos compreendem o conteúdo e se as metodologias aplicadas estão adequadas para o público específico.

Na elaboração da SD, considerou-se as bases da AS com as tipologias dos conteúdos para cada etapa da aplicação, totalizando três etapas apresentadas a seguir.

A primeira etapa, referente à Atividade 1, funcionou como uma avaliação diagnóstica para identificar os subsunçores e/ou organizadores prévios presentes na estrutura cognitiva dos alunos, de modo que essas informações pudessem nortear $o$ andamento da etapa seguinte.

A segunda etapa compreendia as Atividades 2,3,4,5 e 6 e teve a finalidade de promover uma assimilação das novas informações a respeito da EAN por meio da diferenciação progressiva.

Por fim, a terceira etapa, relativa à Atividade 7, buscou envolver os novos conteúdos de aprendizagem a partir das novas informações incorporadas com os subsunçores anteriores por meio da reconciliação integrativa.

Diante da problemática da pesquisa, do objetivo e da justificativa descritos previamente neste artigo, é apresentada no Quadro 1 a estrutura geral da SD interdisciplinar com foco na temática Nutrição, com as etapas e seus respectivos objetivos, justificativa e a duração prevista de cada atividade. 
Quadro 1: Estrutura geral das atividades da SD

\begin{tabular}{|c|c|c|c|}
\hline Etapas / atividades & Objetivo(s) da atividade & Justificativa & Duração \\
\hline $\begin{array}{l}\qquad \text { Etapa 1 } \\
\text { Atividade 1: Avaliação diagnósti- } \\
\text { ca - Questionário de Frequência } \\
\text { Alimentar (QFA) }\end{array}$ & $\begin{array}{l}\text { Conhecer as informações que os } \\
\text { alunos já possuem a respeito do } \\
\text { conteúdo, assim como classificar } \\
\text { seus interesses e aptidões acerca } \\
\text { do tema. }\end{array}$ & $\begin{array}{l}\text { Com base em Haydt (2000), a avaliação di- } \\
\text { agnóstica possibilita verificar em que medida } \\
\text { os conhecimentos anteriores ocorreram e o } \\
\text { que se faz necessário planejar para selecio- } \\
\text { nar as dificuldades encontradas. }\end{array}$ & 1h/aula \\
\hline $\begin{array}{l}\text { Etapa } 2 \\
\text { Atividade 2: Roda da conversa, } \\
\text { leitura de um poema e interpre- } \\
\text { tação de texto - apresentação } \\
\text { da problemática alimentação } \\
\text { saudável }\end{array}$ & $\begin{array}{l}\text { Envolver os alunos em uma dis- } \\
\text { cussão acerca da alimentação } \\
\text { saudável, a fim de discutir o ponto } \\
\text { de vista de cada um. }\end{array}$ & $\begin{array}{l}\text { A roda da conversa possibilita uma intera- } \\
\text { ção dinâmica entre os alunos, pois segundo } \\
\text { Krasilchik (2005), o ensino exclusivamente } \\
\text { informativo, centrado no professor, esta- } \\
\text { belece um clima de apatia e desinteresse } \\
\text { entre os alunos, o que impede a interação } \\
\text { necessária ao verdadeiro aprendizado. }\end{array}$ & 1h/aula \\
\hline $\begin{array}{l}\text { Atividade 3: Pesquisa bibliográ- } \\
\text { fica e produção de cartazes em } \\
\text { grupo - analisando os grupos } \\
\text { alimentares }\end{array}$ & $\begin{array}{l}\text { Distinguir os diferentes grupos } \\
\text { alimentares, seus respectivos nutri- } \\
\text { entes, benefícios à saúde e demais } \\
\text { características relevantes; } \\
\text { Favorecer a interação entre os alu- } \\
\text { nos a partir do trabalho em grupo, } \\
\text { fomentando a qualidade da apre- } \\
\text { ndizagem e a aquisição de novos } \\
\text { conhecimentos. }\end{array}$ & $\begin{array}{l}\text { A pesquisa bibliográfica é feita a partir do } \\
\text { levantamento de referências teóricas já } \\
\text { publicadas, que permite conhecer o que já } \\
\text { se sabe acerca de um assunto (FONSECA, } \\
2002 \text { ); } \\
\text { Segundo Freire (2003), o trabalho em grupo } \\
\text { possui objetivos mútuos, em que cada um } \\
\text { dos participantes assume seu papel com } \\
\text { identidade própria, porém internaliza o outro } \\
\text { dentro de si, criando assim um compromisso } \\
\text { entre seus membros. }\end{array}$ & 2h/aula \\
\hline $\begin{array}{l}\text { Atividade 4: Aula prática - oficina } \\
\text { de culinária (produção de bolinho } \\
\text { de banana na cozinha central do } \\
\text { município) }\end{array}$ & $\begin{array}{l}\text { Estimular os alunos a se envolver- } \\
\text { em com os alimentos, provocando } \\
\text { o interesse em conhecer novos sa- } \\
\text { bores e procurar alternativas mais } \\
\text { saudáveis em sua rotina alimentar. }\end{array}$ & $\begin{array}{l}\text { As aulas práticas podem ajudar no desen- } \\
\text { volvimento de conceitos científicos, além de } \\
\text { permitir que os alunos aprendam como abor- } \\
\text { dar objetivamente o mundo em que vivem e } \\
\text { como desenvolver soluções para possíveis } \\
\text { problemas (LUNETTA, 1991). }\end{array}$ & 2h/aula \\
\hline $\begin{array}{l}\text { Atividade 5: Teatro de fantoches } \\
\text { - alimentação saudável e grupos } \\
\text { alimentares }\end{array}$ & $\begin{array}{l}\text { Permitir que os alunos se envolvam } \\
\text { ativamente com a temática, partici- } \\
\text { pando de um roteiro pertinente aos } \\
\text { hábitos saudáveis de vida e refor- } \\
\text { çando os conteúdos a respeito dos } \\
\text { grupos alimentares. }\end{array}$ & $\begin{array}{l}\text { O teatro é uma ação educativa crítica e trans- } \\
\text { formadora, caracterizada como uma prática } \\
\text { de liberdade que possibilita o processo cria- } \\
\text { tivo e construtivo, com participação ativa e de } \\
\text { modo humanizado (MORIN, 2009). }\end{array}$ & 1h/aula \\
\hline $\begin{array}{l}\text { Atividade 6: Visita ao agricultor } \\
\text { familiar }\end{array}$ & $\begin{array}{l}\text { Proporcionar aos alunos o con- } \\
\text { tato com setores de produção dos } \\
\text { alimentos que lhe são oferecidos na } \\
\text { escola. }\end{array}$ & $\begin{array}{l}\text { As atividades educativas extraclasse são } \\
\text { ações que exploram ambientes externos, } \\
\text { despertam a criatividade, além de estimula- } \\
\text { rem a busca pelo conhecimento. }\end{array}$ & 1h/aula \\
\hline $\begin{array}{l}\text { Etapa } 3 \\
\text { Atividade 7: Avaliação final - Lan- } \\
\text { che atitudinal e ficha reflexiva }\end{array}$ & $\begin{array}{l}\text { Observar o comportamento dos alu- } \\
\text { nos em uma situação de oferta de al- } \\
\text { imentos saudáveis e não saudáveis, } \\
\text { ao mesmo tempo que os mesmos } \\
\text { façam considerações de seus juízos } \\
\text { de valor a respeito dos alimentos se- } \\
\text { lecionados para consumo. }\end{array}$ & $\begin{array}{l}\text { A oferta do lanche permitirá uma avaliação } \\
\text { atitudinal da turma, pois segundo Zabala } \\
\text { (2010), este tipo de conteúdo possibilita o } \\
\text { aluno a posicionar-se perante o que apre- } \\
\text { ndem, pois são detentores dos fatos e de } \\
\text { como resolvê-los, sendo necessária uma } \\
\text { postura frente a eles. }\end{array}$ & 1h/aula \\
\hline
\end{tabular}

Fonte: Menon (2019). 
Nessa perspectiva, inferimos que os pressupostos teórico-metodológicos de Zabala (2010) e os aportes da teoria da AS fornecem elementos necessários para a elaboração, aplicação e avaliação de uma SD interdisciplinar de EAN, que serve como um complemento aos conteúdos fornecidos pelo livro didático do quinto ano do Ensino Fundamental.

A apresentação da SD, o detalhamento de suas atividades e as orientações de uso compõe um caderno pedagógico em meio eletrônico disponível em https://educapes. capes.gov.br/handle/capes/43172. No documento encontram-se as instruções para a realização das atividades, os materiais utilizados em sua aplicação, os questionários, as apresentações em slides, as receitas, os roteiros teatrais e as imagens ilustrativas. Para mais informações, entre em contato pelo e-mail: amanda_menon@hotmail.com.

Algumas considerações

Ao considerar que a formação de hábitos alimentares ocorre desde a infância e que os mesmos podem se perpetuar na vida de um indivíduo, buscou-se por meio da SD incitar a atenção dos alunos para assuntos em torno da alimentação e da nutrição, procurando proporcionar por meio das atividades vivências à valorização de práticas alimentares saudáveis, de modo que os alunos pudessem reproduzi-las em seu cotidiano.

Nesse sentido, observou-se que a Atividade 1 permitiu traçar um diagnóstico alimentar dos alunos e identificar subsunçores em torno do tema, resgatando os conteúdos conceituais que os mesmos tinham previamente sobre a nutrição. Tais conceitos não foram considerados definitivos, pois as novas experiências possibilitariam, segundo o que nos afirmam os referenciais teóricos, o enriquecimento do conhecimento. Ao responderem o questionário de frequência alimentar, dados referentes ao seu comportamento alimentar foram resgatados. Como evidências, ressalta-se a preferência por alimentos doces e frutas, e uma rejeição acentuada a alguns vegetais, entre eles: rúcula, abobrinha e berinjela. Quanto às percepções em torno da qualidade da própria alimentação, os mesmos tiveram opiniões variadas, como considerar sua rotina alimentar equilibrada ao se interessar por alimentos benéficos à saúde, porém, cientes de que consomem alimentos de baixo valor nutricional devido à afinidade com o sabor.

As atividades da segunda etapa da pesquisa reuniram registros referentes aos conteúdos procedimentais dos alunos, com o intuito de diferenciar progressivamente as noções prévias de nutrição com as novas informações. 
Por meio da Atividade 2, a turma pôde argumentar a respeito de seus diferentes pontos de vista acerca de hábitos alimentares saudáveis, com discussões que incentivaram a formação de opinião, o discernimento e o respeito às opiniões alheias. A roda de conversa já tinha sido realizada outras vezes pela professora regente, pois a atividade pertence à disciplina de Português e foi adaptada com o tema em questão. A apresentação dos alimentos de forma lúdica nas imagens dos slides do poema elucidou um atrativo, visto que as mesmas foram citadas inúmeras vezes nas discussões.

Em paralelo, a elaboração dos cartazes em grupo durante a Atividade 3 resgatou novamente o interesse por figuras de alimentos bem apresentados, a qual os alunos se dividiram em equipes e reforçaram o conteúdo dos grupos alimentares, visto anteriormente na disciplina de Ciências.

A Atividade 4 consistiu em uma aula prática para trabalhar com frações, conteúdo relacionada à disciplina de Matemática, com o intuito de estimular a busca por novas alternativas alimentares por meio do ato de cozinhar. Foi destacado que muitas vezes estudamos um conteúdo sem saber ao certo como utilizá-lo, mas que podem ser úteis em situações cotidianas, como é o caso das frações. Além disso, a receita retomou o conceito de medidas caseiras, reforçou os grupos alimentares e os nutrientes dos ingredientes. Os alunos expuseram lembranças de experiências relacionadas à atividade, como o uso de uma pizza para trabalhar o fracionamento do alimento, e a memória das medidas caseiras ao preparar refeições junto à família, o que se considera relevante na diferenciação progressiva da EAN.

Dando sequência às abordagens lúdicas, a quinta atividade reforçou um conteúdo de Artes ao desenvolver um roteiro de teatro acerca da alimentação saudável, da função dos alimentos, assim como seus benefícios ou prejuízos ao corpo humano. Foram utilizados fantoches e uma caixa misteriosa com diversos alimentos, a fim de instigá-los a participar da dinâmica de divisão dos alimentos em seus respectivos grupos. A proposta obteve um resultado positivo, visto que a participação dos alunos foi satisfatória e observou-se uma evolução na compreensão de conceitos relacionados aos grupos alimentares.

Para fechar a etapa da diferenciação progressiva, os alunos visitaram uma propriedade rural de um agricultor que fornece insumos à alimentação escolar da escola, resgatando conteúdos de Geografia relacionados aos setores de produção e qualidade do solo. A turma pôde esclarecer dúvidas e curiosidades com o produtor 
rural, o qual permitiu a locomoção entre as hortas e pomares. Após a visita, foi solicitada uma resenha a respeito de algum alimento observado durante o passeio e suas respectivas características nutricionais.

Por fim, a sétima e última atividade reuniu registros dos conteúdos atitudinais dos alunos, assim como os juízos de valor e percepções acerca de suas escolhas, reconciliando integrativamente as novas aprendizagens com os conceitos subsunçores observados no início da pesquisa. Foi disponibilizado um lanche para que os alunos se servissem livremente com alimentos de alto valor nutritivo, como frutas, suco natural, iogurte, alimentos integrais e sanduíches naturais, e com alimentos de baixo valor nutritivo, como bolo confeitado, salgados fritos e refrigerantes. Após a refeição, os alunos responderam a uma ficha com questões relacionadas à SD como um todo, para que pudesse haver uma percepção se a aprendizagem de EAN foi significativa ou não. Foi observado que os alunos, em geral, fizeram escolhas equilibradas, consumindo alimentos nutritivos em conjunto com as opções mais calóricas, que lhes agradavam. Tal procedimento foi considerado satisfatório, visto que os alunos consideraram o equilíbrio na escolha dos alimentos, optando em consumir conscientemente os alimentos que faziam bem à saúde juntamente com aqueles de sua preferência.

A partir da pesquisa desenvolvida, inferiu-se que as atividades realizadas possuíram caráter prático e teórico. Apesar de a escola possuir um currículo próprio, as atividades foram planejadas a partir do conteúdo programático do livro didático do quinto ano do Ensino Fundamental, sendo consideradas enriquecedoras por mobilizar os alunos a contextualizar e aplicar o conteúdo de EAN em atividades diárias.

Como possíveis desdobramentos, estima-se que as escolas realizem um trabalho em conjunto entre nutricionistas e educadores, com vista à elaboração de materiais didáticos adequados ao ambiente escolar em linguagem apropriada à faixa etária, unindo, dessa forma, os saberes profissionais de áreas distintas em prol de uma aprendizagem significativa. Entre as ações, propõem-se a implantação de hortas escolares, a exibição de documentários para conscientização dos problemas causados pelo excesso de peso, visitas ao supermercado para aprendizagem de leitura e análise dos rótulos alimentares, incentivar merendeiras, professores e mães em criações de receitas a serem servidas na alimentação escolar, com relato de experiências pessoais, promover oficinas de culinária com aproveitamento integral de 
alimentos, com vista a evitar desperdícios, desenvolver atividades reflexivas quanto aos benefícios dos grupos alimentares para o organismo, dentre outras.

Deve-se ressaltar que, embora essa SD seja pedagogicamente dividida em etapas e atividades, sua utilização em sala de aula torna-se passível de adaptações que são naturalmente necessárias mediante a aplicação com outro público (Ensino Fundamental - séries finais, Ensino Médio e Ensino Superior), em outros momentos, em uma proposta interdisciplinar que considera diversas disciplinas e que acomoda outros temas integradores.

Em suma, averiguou-se (mediante a coleta e análise dos dados que não foram o foco deste artigo) que essa SD pôde contribuir para que alunos em idade escolar refletissem a respeito de seu comportamento alimentar, incentivando mudanças positivas nas escolhas de alimentos com melhor composição nutricional. Além disso, constatou-se que organizadores prévios acerca da EAN, quando bem articulados, proporcionam Aprendizagem Significativa em torno dessa temática, o que contribui com a saúde e o bem-estar desde a infância.

Mediante reflexões referentes ao percurso realizado durante a elaboração deste material e considerando que os hábitos de vida são construídos de forma lenta e gradual, algumas questões emergiram ao longo da pesquisa e serão objetos de futuras investigações: De que forma as atividades de EAN podem ser trabalhadas para de fato modificar os hábitos alimentares dos alunos? Como assegurar que a escola seja um espaço que garanta as boas práticas alimentares? De que modo os adolescentes lidam com esse assunto?

Espera-se que a SD proposta sirva de apoio e inspiração a nutricionistas, a professores e equipes pedagógicas que estejam interessados em desenvolver projetos de EAN em suas escolas. 


\section{Mediation of students' feeding through a Didactic Sequence}

\section{Abstract}

This paper presents the structuring of a Didactic Sequence with interdisciplinary activities about the Nutrition theme, which aims to contribute to students' effective eating choices. The didactic sequence was structured in three stages guided by the theory of Meaningful Learning (ML) in which seven activities were proposed, in full, taking into account the school context. In addition, we take Human Nutrition as an integrative theme of the school subjects and textbook content in the fifthgrade, Elementary School. This elaboration was directed to a public-school class in northern Paraná, composed of 22 students aged between nine and eleven years of both sexes. The data was collected by using the Didactic Sequence application were categorized and analyzed in the light of the theoretical assumptions of Discursive Textual Analysis. This analytical movement led to the conclusion that there was a broadening of students' understanding of Nutrition concepts from the perspective of Meaningful Learning, a fact that led them to engage with the theme, motivating them to seek an adequate and healthy diet. Moreover, this process allowed us to infer that with minor adaptations this proposal can be used to address a broader theme that is Food and Nutrition Education.

Keywords: Meaningful learning. Food and nutrition education. Interdisciplinarity. Didactic sequence.

\section{Notas}

1 Fundação vinculada ao Ministério da Educação (MEC) que atua na expansão e consolidação da pós-graduação stricto sensu em todo o país (BRASIL, 2016).

2 A proposta da interdisciplinaridade no ambiente escolar possibilita o encontro de experiências que permitem o englobamento de conteúdos que tragam um significado mais próximo da realidade dos alunos. $\mathrm{O}$ conceito interdisciplinar será apresentado adiante, nos embasamentos teóricos da pesquisa.

3 A Segurança Alimentar e Nutricional consiste na realização do direito de todos ao acesso regular e permanente a alimentos de qualidade, em quantidade suficiente, sem comprometer $\mathrm{o}$ acesso a outras necessidades essenciais, tendo como base práticas alimentares promotoras de saúde que respeitem a diversidade cultural e sejam ambientáveis (BRASIL, 2006).

4 Neste artigo não nos dedicamos a apresentar essas análises e os resultados provenientes delas, todavia a completude dessas informações pode ser acessada em Menon (2019).

\section{Referências}

ALMEIDA, C. M. M; SCHEUNEMANN, C. M. B; LOPES, Formação continuada para professores em serviço do Ensino Fundamental Séries Iniciais: Aprendizagem Significativa e mapas conceituais. RBECM, Passo Fundo, v. 2, n. 2, p. 253-276, 2019. Disponível em: <http://seer.upf. br/index.php/rbecm/article/view/9957/114115176>. Acesso em: 14. 02. 2020.

ALMEIDA, R. T. A literatura como abordagem facilitadora e potencializadora no ensino de ciências: uma experiência na formação de professores. 2013. Nilópolis: IFRJ, 2013. Dissertação (Mestrado Profissional em Ensino de Ciências) - Instituto Federal de Educação, Ciência e Tecnologia, 2013. 
AUSUBEL, D. Aquisição e retenção de conhecimentos: uma perspectiva cognitiva. Lisboa: Plátano Edições Técnicas, 2003.

AUSUBEL, D; NOVAK, J; HANESIAN, H. Psicologia educacional. Rio de Janeiro: Editora Interamericana, 1980.

BERNARDELLI, M. S. Encantar para ensinar: um procedimento alternativo para o ensino de Química. In: CONVENÇÃO BRASIL LATINO AMÉRICA, CONGRESSO BRASILEIRO E ENCONTRO PARANAENSE DE PSICOTERAPIAS CORPORAIS, 2004, Foz do Iguaçu. Anais [...]. Foz do Iguaçu: Centro Reichiano, 2004. Disponível em: <http://www.centroreichiano.com. br/artigos/Anais-2004/BERNARDELLI-Marlize-Spagolla-Encantar.pdf>. Acesso em: 03.10.2019.

BOGDAN, R.; BIKLEN, S. Investigações qualitativas em educação. Portugal: Porto Editora, 1994.

BRASIL. Lei no 11.346, de 15 de setembro de 2006. Cria o Sistema Nacional de Segurança Alimentar e Nutricional - SISAN com vistas em assegurar o direito humano à alimentação adequada e dá outras providências. Brasília, 2006. Disponível em: <http://www.planalto. gov.br/ccivil_03/_Ato2004-2006/2006/Lei/L11346.htm>. Acesso em: 10.10.2019.

BRASIL. Ministério da Educação. Coordenação de Aperfeiçoamento de Pessoal em Nível Superior. Documento de Área - Ensino, 2016. Disponível em: <https://pos.cepae.ufg.br/up/480/o/ DOCUMENTO_DE_AREA_ENSINO_2016_final.pdf>. Acesso em: 21.11.2019.

BRASIL. Ministério da Educação. Secretaria de Educação Básica. Base Nacional Comum Curricular. Brasília, 2018. Disponível em: <http://basenacionalcomum.mec.gov.br/images/ BNCC_EI_EF_110518_versaofinal_site.pdf> Acesso em: 10.10.2019.

BRASIL. Ministério da Educação. Secretaria de Educação Básica. Diretrizes Curriculares Nacionais da Educação Básica. Brasília, 2013. Disponível em: <http://portal.mec.gov.br/index. php?option=com_docman\&view=download\&alias=15548-d-c-n-educacao-basica-nova-pdf\&Itemid=30192 > . Acesso em: 12.11.2019.

BRASIL. Secretaria de Educação Fundamental. Parâmetros curriculares nacionais: Tema Transversal Saúde. Brasília, 1997. Disponível em: <http://portal.mec.gov.br/seb/arquivos/pdf/ saude.pdf>. Acesso em: 06.10.2019.

COOL, C. et al. O construtivismo na sala de aula. São Paulo: Ática, 1998.

FAZENDA, I. C. A. Interdisciplinaridade: um projeto em parceria. São Paulo: Edições Loyola, 1991.

FONSECA, J. J. S. Metodologia da pesquisa científica. Fortaleza: UEC, 2002.

FREIRE, M. O que é um grupo? In: FREIRE, M. (org.). Grupo: indivíduo, saber e parceria: malhas do conhecimento. São Paulo: Espaço Pedagógico, 2003.

GALLINA, L. S et al. Hábito alimentar do professor: importante elemento para a promoção da saúde no ambiente escolar. Revista Simbio-Logias, Botucatu, v. 6, n. 9, p. 105-116, 2013.

HAYDT, R. C. Avaliação do processo ensino-aprendizagem. São Paulo: Ática, 2000.

KRAMER, S. Autoria e autorização: questões éticas na pesquisa com crianças. Cadernos de Pesquisa, São Paulo, n. 116, p. 41-59, 2002. Disponível em: <http://www.scielo.br/pdf/cp/n116/14398. pdf>. Acesso em: 18.11.2019. 
KRASILCHIK, M. Prática de ensino de biologia. São Paulo: Editora Universidade de São Paulo, 2005.

LUNETTA, V. Atividades práticas no ensino da Ciência. Revista Portuguesa de Educação, Braga, v. 2, n. 1, p. 81-90, 1991.

MENON, A. M. Sequência Didática Interdisciplinar de Educação Alimentar e Nutricional na perspectiva da Aprendizagem Significativa e dos Saberes Docentes. 2019. 159 f. Dissertação (Mestrado Profissional em Ensino) - Universidade Estadual do Norte do Paraná, Cornélio Procópio, 2019.

MENON, A. M; COELHO NETO, João; BERNARDELLI, M. S. Abordagens da alimentação e nutrição nas disciplinas do Ensino Fundamental: uma revisão sistemática de literatura. Research, Society and Development, Itabira, v. 7, n. 8, p. 1-19, 2018.

MOREIRA, M. A. Aprendizagem significativa. Brasília: UnB, 1999.

MOREIRA, M. A. Aprendizagem significativa: a teoria e textos complementares. São Paulo: Editora Livraria da Física, 2011.

MORIN, E. Educação e complexidade: os sete saberes e outros ensaios. São Paulo: Cortez, 2009. ORGANIZAÇÃO DAS NAÇÕES UNIDAS (ONU). Declaração Universal dos Direitos Humanos. Nova Iorque, 1948. Disponível em: < https://nacoesunidas.org/wp-content/uploads/2018/10/ DUDH.pdf>. Acesso em: 02.10.2019.

RETONDARIO, A.; NADAL, J. Conhecimento de professores de uma escola estadual sobre o programa nacional de alimentação escolar e a formação de hábitos e práticas alimentares. Revista Nutrir, Ponta Grossa, v. 1, n. 2, p. 1-11, 2015.

SILVEIRA, M. das G. G. Alimentação do pré-escolar e escolar. São Paulo: Editora Vozes, 2015. ZABALA, Antoni. A prática educativa: como ensinar. Porto Alegre: Artmed, 2010. 